\title{
Case Report: Application and Limitations of a Plant-Based Diet Formulated for a Cat With Feline Lower Urinary Tract Disease
}

\section{OPEN ACCESS}

Edited by:

Joseph Wakshlag,

Cornell University, United States

Reviewed by: Alessia Candellone, University of Turin, Italy Maria Grazia Cappai University of Sassari, Italy

${ }^{*}$ Correspondence: Adronie Verbrugghe averbrug@uoguelph.ca

${ }^{\dagger}$ Present address: Sarah K. Abood Sit, Stay, Speak Nutrition, LLC, Dimondale, MI, United States

Specialty section:

This article was submitted to Animal Nutrition and Metabolism, a section of the journa

Frontiers in Veterinary Science

Received: 25 January 2021 Accepted: 05 March 2021 Published: 09 April 2021

Citation: Dodd SAS, Grant C, Abood SK and Verbrugghe A (2021) Case Report: Application and Limitations of a Plant-Based Diet Formulated for a Cat With Feline Lower Urinary Tract Disease. Front. Vet. Sci. 8:658265. doi: 10.3389/fvets.2021.658265

\author{
Sarah A. S. Dodd ${ }^{1,2}$, Caitlin Grant ${ }^{1}$, Sarah K. Abood ${ }^{1+}$ and Adronie Verbrugghe ${ }^{1 *}$ \\ ${ }^{1}$ Department of Clinical Studies, Ontario Veterinary College, University of Guelph, Guelph, ON, Canada, ${ }^{2}$ Department of \\ Population Medicine, Ontario Veterinary College, University of Guelph, Guelph, ON, Canada
}

A 2-year-old male castrated domestic shorthair cat was presented for recommendations for dietary management of chronic FLUTD using a strictly plant-based diet as per the stipulations of the cat's owner. The cat had a history of urethral obstruction of unknown etiology, persistent marked struvite crystalluria, and persistent inappropriate elimination. Commercial plant-based products meeting the nutritional recommendations for maintenance of adult cats with the lowest concentration of struvite precursors were identified, but the cat would not eat them. At the request of the client, a homemade plant-based diet was formulated with the intention of increasing water intake and promoting acidic, dilute urine. Urine concentration was able to be decreased somewhat and struvite crystalluria resolved, but the urine remained more alkaline than intended. The cat clinically improved and no further FLUTD episodes were reported by the client.

\section{Keywords: crystalluria, feline nutrition, struvite, urethral obstruction, vegan}

\section{INTRODUCTION}

Feline lower urinary tract disorders (FLUTD) are common, potentially life-threatening problems in cats (1). Nearly $20 \%$ may be attributable to urethral obstruction, with $10-30 \%$ of obstructions attributable to urolithiasis (1-3). One of the most common uroliths are magnesium ammonium phosphate (struvite) $(4,5)$. Struvite has also been reported to be a common component of urethral plugs (6). Risk factors for FLUTD include breed, sex, reproductive status, age, body condition score (BCS), indoor and outdoor access, activity, number of pets in the household, potential stressors, litter management, diet, and water intake $(1,7)$. The focus of the case presented here is on management of nutritional risk factors.

\section{CASE PRESENTATION}

A 2-year-old male castrated domestic shorthair cat was presented to his veterinarian for suspect urethral obstruction. On presentation, he was documented to have a BCS of 3 on a 5-point scale, weighing $4.85 \mathrm{~kg}$. A full, hard bladder was palpated, and white, gritty material was noted at the tip of his penis. Pre-anesthetic bloodwork revealed few abnormalities (see Table 1). A catheter was passed with some resistance, allowing emptying of the bladder. Copious amounts of "sand" were present in the urine. Urine $\mathrm{pH}$ was 8.0, cocci bacteria and large quantities of struvite crystals were detected (Table 2). Due to the presence of struvite crystals in the urine and small uroliths visualized by ultrasound, a canned feline veterinary therapeutic diet formulated for dissolution and prevention 
TABLE 1 | Hematology and serum biochemistry at time of urethral obstruction.

\begin{tabular}{|c|c|c|}
\hline Parameter & Units & Result \\
\hline \multicolumn{3}{|l|}{ Hematology } \\
\hline $\mathrm{RBC}$ & $\times 10^{12} / L$ & 9.09 \\
\hline HCT & $\%$ & 40.3 \\
\hline HGB & $g / d L$ & 11.8 \\
\hline MCV & $\mathrm{fL}$ & 44.3 \\
\hline $\mathrm{MCH}$ & $\mathrm{Pg}$ & 13.0 \\
\hline $\mathrm{MCHC}$ & $\mathrm{g} / \mathrm{dL}$ & 29.3 \\
\hline RDW & $\%$ & 22.7 \\
\hline Retic & $\mathrm{K} / \mu \mathrm{L}$ & 8.2 \\
\hline WBC & $\times 10^{9} / \mathrm{L}$ & 14.61 \\
\hline $\mathrm{Neu}$ & $\times 10^{9} / \mathrm{L}$ & 11.01 \\
\hline Lym & $\times 10^{9} / \mathrm{L}$ & 2.91 \\
\hline Mono & $\times 10^{9} / \mathrm{L}$ & 0.31 \\
\hline Eos & $\times 10^{9} / \mathrm{L}$ & 0.14 \\
\hline Baso & $\times 10^{9} / \mathrm{L}$ & 0.24 \\
\hline PLT & $\mathrm{K} / \mu \mathrm{L}$ & 397 \\
\hline MPV & $\mathrm{fL}$ & 15.8 \\
\hline Plateletcrit & $\%$ & 0.63 \\
\hline \multicolumn{3}{|l|}{ Biochemistry } \\
\hline Glucose & $\mathrm{mmol} / \mathrm{L}$ & 19.26 \\
\hline Creatinine & $\mathrm{mmol} / \mathrm{L}$ & 122 \\
\hline Urea & $\mathrm{mmol} / \mathrm{L}$ & 7.0 \\
\hline Total protein & $g / L$ & 63 \\
\hline Albumin & $g / L$ & 32 \\
\hline Globulin & $g / L$ & 31 \\
\hline Albumin/globulin & Ratio & 1.0 \\
\hline ALT & $\mathrm{U} / \mathrm{L}$ & 38 \\
\hline ALKP & $\mathrm{U} / \mathrm{L}$ & 38 \\
\hline $\mathrm{Na}$ & $\mathrm{mmol} / \mathrm{L}$ & 155 \\
\hline K & $\mathrm{mmol} / \mathrm{L}$ & 8.0 \\
\hline $\mathrm{Na} / \mathrm{K}$ & Ratio & 19 \\
\hline $\mathrm{Cl}$ & $\mathrm{mmol} / \mathrm{L}$ & 118 \\
\hline Osm & $\mathrm{mmol} / \mathrm{kg}$ & 330 \\
\hline
\end{tabular}

of struvite uroliths was recommended (Table 3). Previously, the cat had been fed commercial plant-based diets (Table 3). The cat was discharged with amoxicillin-clavulanic acid $(62.5 \mathrm{mg}$ Q12h PO, 10 days), prazosin (0.5 mg Q12h PO, 15 days, then $0.5 \mathrm{mg}$ Q24h, 15 days), buprenorphine (0.08 mg Q8h PO, 16 days, tapering to $0.04 \mathrm{mg} \mathrm{Q} 24 \mathrm{~h}$ as required), and robenacoxib (6 mg PO SID, 6 days). Alprazolam (0.5 mg Q12h, 14 days) was also prescribed for underlying anxiety. The cat re-presented twice over the following 5 weeks with acute difficulty urinating, vocalizing, straining, and urinating outside of the litter box. No abnormalities were detected on physical examinations and urinalyses revealed improvement in urine acidity with fewer struvite crystals. Against recommendations, the client discontinued the therapeutic food as it contained animal products, and the cat was returned to his previous commercial plant-based diet.
One month later, the cat was referred to the Ontario Veterinary College Health Sciences Centre Clinical Nutrition Service for consultation regarding plant-based dietary management for FLUTD. The owner was vegan and required that they feed the cat a plant-based diet in order to comply with their ethics. On presentation, the cat had a BCS of 5/9 (8), weighing $5.0 \mathrm{~kg}$. Nutritional evaluation revealed risk factors based on the WSAVA Nutritional Evaluation Checklist (9), including living in a multi-cat house, ongoing urinary signs, and being fed an unconventional diet. The cat's resting energy requirement $(\mathrm{RER})$ was estimated using: $\left(\mathrm{BW}^{0.75} * 70 \mathrm{kcal}\right)=250$ kcal (10). Given the cat's activity, current bodyweight and BCS, his daily energy intake was estimated to be RER $* 1.2=300 \mathrm{kcal}$. A recommendation was made for a commercial feline veterinary therapeutic diet formulated to manage signs of FLUTD (Table 3), which was declined by the client as it contained animal products. After discussing the challenges related to management with a plant-based diet, commercial plant-based diets were identified as alternative strategies. While detailed nutrient profiles are not typically available for many commercial plant-based diets available in Canada, nutrient analyses had been performed as part of a research project conducted by the authors (11). Diets meeting the AAFCO adult maintenance recommendations with the lowest concentration of struvite precursors were identified (Table 3). Based on energy density, food doses were recommended to combine kibble and canned food in a 50:50 ratio. The recommendation was made for the cat to be fed $35 \mathrm{~g}$ (143 kcal) kibble and $150 \mathrm{~g}(148 \mathrm{kcal})$ canned food, allowing for $10 \mathrm{kcal}$ (3\% of daily energy intake) to be given as treats or snacks. The client was advised on the energy and nutrient content of suitable treats and snacks. Recommendations were made to encourage water intake, feed small, frequent meals, and to supplement the diet with eicosapentaenoic acid and docosahexaenoic acid (EPA+DHA) at a dose equivalent to $0.5 \%$ of the diet on a dry matter basis (7). Recommendations to increase water intake included adding water to food, adding palatants to water, providing multiple water dishes in different locations, different materials (e.g., ceramic or metal), offering wide dishes to avoid whisker stimulation, and drinking fountains.

Three months later, the cat re-presented to his veterinarian for inappetence and weight loss. His bodyweight was recorded at $4.30 \mathrm{~kg}$, though BCS was still documented as 3 on a 5 -point scale. According to dietary anamnesis the cat would not eat the canned diet, nor accept soaked kibble or the DHA+EPA supplement recommended by the Clinical Nutrition Service, and he had continued to be fed the commercial plant-based diet he had been fed prior to the urethral obstruction (Table 3). Urine was collected by the client using non-absorbent litter (Table 2). A veterinary therapeutic dissolution diet was again discussed with the client as being the most evidence-based solution to mitigate risk of recurrent FLUTD signs, but the client declined this recommendation. Mirtazapine (2 $\mathrm{mg}$ Q24-48h as required) was prescribed to stimulate food intake. Though no dietary change was implemented, recheck examination 3 weeks later revealed a slight increase in body weight from 4.30 to $4.43 \mathrm{~kg}$. Four months later, the cat re-presented for decreased urine output. At that time his body weight was $4.51 \mathrm{~kg}$ and his BCS was documented 
TABLE 2 | Selected urinalysis characteristics from time of urethral obstruction to end of follow-up.

\begin{tabular}{|c|c|c|c|c|c|c|c|c|c|c|c|}
\hline \multirow[t]{2}{*}{ Parameter } & \multicolumn{11}{|c|}{ Date } \\
\hline & 12/3/19 & $25 / 3 / 19$ & 18/4/19 & 1/8/19 & 1/10/19 & 29/10/19 & $8 / 1 / 20$ & 27/1/20 & $14 / 2 / 20$ & $20 / 3 / 20$ & $28 / 4 / 20$ \\
\hline Diet & $\begin{array}{l}\text { Kibble B and C, } \\
\text { Canned B }\end{array}$ & $\begin{array}{l}\text { Therapeutic } \\
\text { canned }\end{array}$ & Kibble B and C & & & & Homemade diet & & Kibble A & & $\begin{array}{l}\text { Kibble A, } \\
\text { Formulated diet }\end{array}$ \\
\hline Weight (kg) & 4.85 & NR & 5.03 & 4.30 & & & 4.51 & & & 5.80 & \\
\hline BCS (/9) & 5 & NR & 5 & 5 & & & 5 & & & 6 & \\
\hline Collection method & Catheterization & Free flow & & Cystocentesis & & & Free flow & & & & Cystocentesis \\
\hline $\begin{array}{l}\text { Urine specific } \\
\text { gravity }\end{array}$ & 1.040 & 1.032 & 1.018 & 1.030 & 1.065 & 1.025 & 1.060 & 1.060 & 1.060 & 1.040 & 1.038 \\
\hline pH & 8.0 & 6.0 & 8.0 & 8.5 & 7.5 & 8.0 & 7.0 & 7.0 & 6.0 & 7.0 & 7.0 \\
\hline Protein & $2+$ & $2+$ & - & $1+$ & $1+$ & $2+$ & $1+$ & $1+$ & $1+$ & Trace & Trace \\
\hline Blood & $4+$ & - & - & $3+$ & - & - & - & - & - & - & - \\
\hline Crystals & 10-16 S/hpf & Occasional S & 10-20 S/hpf & 1-5 S/hpf & 3-5 S/hpf & $\begin{array}{l}\text { Minor } \\
\text { amorphous } \\
\text { debris }\end{array}$ & 10-20 S/hpf & $>40$ S/hpf & 1-10 S/hpf & 1-10 S/hpf & - \\
\hline Red blood cells & $4+$ & $\mathrm{N}$ & 20-30/hpf & 50-75/hpf & 15-20/hpf & $\mathrm{N}$ & 0-2/hpf & $\mathrm{N}$ & $\mathrm{N}$ & $\mathrm{N}$ & $<1 / \mathrm{hpf}$ \\
\hline White blood cells & $1+$ & 2-4/hpf & $10-15$ & $0-2 / \mathrm{hpf}$ & $\mathrm{N}$ & $\mathrm{N}$ & $\mathrm{N}$ & $\mathrm{N}$ & $\mathrm{N}$ & $\mathrm{N}$ & $<1 / \mathrm{hpf}$ \\
\hline Bacteria & $1+\operatorname{cocci}$ & $1+\operatorname{cocci}$ & Chains & $\mathrm{N}$ & $\mathrm{N}$ & $\mathrm{N}$ & $\mathrm{N}$ & $1+\operatorname{cocci}$ & $\mathrm{N}$ & $1+\operatorname{cocci}$ & $\mathrm{N}$ \\
\hline
\end{tabular}

-, negative; S, struvite; NR, not reported. 
TABLE 3 | Profile of specific nutrients of interest in commercial plant-based feline diets, compared to the recommended therapeutic diet.

\begin{tabular}{|c|c|c|c|c|c|c|c|c|c|}
\hline & \multirow[t]{2}{*}{ Target } & \multirow{2}{*}{$\begin{array}{l}\text { Recommendec } \\
\text { veterinary }\end{array}$} & \multicolumn{3}{|c|}{ Initial diet } & \multicolumn{2}{|c|}{ Recommended commercial diets } & \multicolumn{2}{|c|}{ Homemade diets } \\
\hline & & & $\begin{array}{l}\text { Plant-based } \\
\text { canned A }\end{array}$ & $\begin{array}{l}\text { Plant-based } \\
\text { kibble A }\end{array}$ & $\begin{array}{l}\text { Plant-based } \\
\text { kibble B }\end{array}$ & $\begin{array}{l}\text { Plant-based } \\
\text { canned C }\end{array}$ & $\begin{array}{l}\text { Plant-based } \\
\text { kibble C }\end{array}$ & $\begin{array}{l}\text { Client's } \\
\text { homemade } \\
\text { diet }\end{array}$ & $\begin{array}{l}\text { Formulated } \\
\text { homemade } \\
\text { diet }\end{array}$ \\
\hline Energy (kcal/100 g) & - & 81.5 & 109.9 & 386.1 & 441.3 & 407.5 & 98.7 & 101.6 & 123.1 \\
\hline $\begin{array}{l}\text { Base excess } \\
(\mathrm{mmol} / \mathrm{kg} \mathrm{DM})\end{array}$ & $<250$ & 422 & -51 & -180 & -160 & -172 & -72 & -45 & -398 \\
\hline \multicolumn{10}{|l|}{ Nutrient (g/100 kcal) } \\
\hline Moisture & Moist & 100.0 & 64.6 & 16.1 & 11.8 & 75.5 & 10.9 & 76.3 & 54.5 \\
\hline Protein & $7.0-9.0$ & 9.8 & 7.7 & 8.3 & 6.7 & 8.6 & 7.0 & 6.1 & 8.2 \\
\hline Methionine & $0.10-0.38$ & 0.18 & 0.11 & 0.18 & 0.16 & 0.13 & 0.17 & 0.12 & 0.32 \\
\hline \multicolumn{2}{|c|}{ Methionine + Cystine >0.2 } & 0.31 & 0.15 & 0.24 & 0.24 & 0.16 & 0.25 & 0.15 & 0.54 \\
\hline Taurine & $>0.05$ & 0.11 & 0.03 & 0.03 & 0.05 & 0.03 & 0.06 & 0.06 & 0.24 \\
\hline Fat & $2.3-4.6$ & 4.3 & 2.3 & 3.0 & 4.9 & 2.2 & 3.4 & 5.1 & 4.2 \\
\hline$E P A+D H A$ & $>0.05$ & 0.17 & 0.00 & 0.01 & 0.01 & 0.00 & 0.01 & 0.01 & 0.16 \\
\hline Calcium & $0.14-0.30$ & 0.26 & 0.30 & 0.20 & 0.28 & 0.16 & 0.18 & 0.24 & 0.28 \\
\hline Phosphorus & $0.13-0.26$ & 0.23 & 0.26 & 0.18 & 0.22 & 0.16 & 0.13 & 0.14 & 0.26 \\
\hline Magnesium & $0.01-0.02$ & 0.01 & 0.05 & 0.04 & 0.04 & 0.05 & 0.02 & 0.04 & 0.02 \\
\hline Sodium & $0.07-0.14$ & 0.33 & 0.12 & 0.04 & 0.08 & 0.08 & 0.17 & 0.04 & 0.18 \\
\hline Potassium & 0.15 & 0.15 & 0.44 & 0.17 & 0.28 & 0.44 & 0.16 & 0.03 & 0.39 \\
\hline Chloride & $>0.20$ & 0.36 & 0.25 & 0.14 & 0.25 & 0.20 & 0.26 & $0.06^{\star}$ & $0.22^{*}$ \\
\hline Sulfur & $>0.05$ & NM & 0.09 & 0.11 & 0.09 & 0.11 & 0.12 & $0.15^{\star}$ & $0.15^{\star}$ \\
\hline
\end{tabular}

* Likely underestimated as content is not reported in the USDA database or Canadian Nutrient File for most food products NM, not measured.

as 5 on a 9-point scale. Free-flow urine was examined again (Table 2), and a feline veterinary therapeutic dissolution diet was recommended, but again declined. The client elected to try to increase water intake and began preparing a home-cooked plant-based diet (Table 4).

Three months later, the cat was re-presented to the Clinical Nutrition service for management of inappetence. Despite the client's concerns about the cat's intake, on presentation the cat weighed $5.8 \mathrm{~kg}$ with a BCS of 6 on a 9-point scale, his heaviest recorded weight. Evaluation of the home-cooked plant-based diet using diet formulation software (Balance $\mathrm{IT}^{\circledR}$ ) revealed the diet to be deficient in numerous nutrients, most notably meeting $0 \%$ of the cat's arachidonic acid requirement, while it provided iodine over 8 times the maximum recommended dose (Table 3 ). On a daily basis, the cat was fed: 1 tbsp homemade food, 2 tbsp of vegetables (pumpkin, green lentils, peas, squash, green beans, or corn), $3 / 4$ cup of kibble B, $1 / 8$ tsp enzyme supplement, $250 \mathrm{mg}$ methionine, and $1 / 8$ tsp psyllium. The diet recipe was reported to have been acquired from a friend and it was unknown where the dosing had been acquired for the supplementation of enzymes, methionine, or psyllium. Treats included commercial plant-based deli slices, non-dairy cheese, potato chips, coconut yogurt, non-dairy sour cream, and dried nori seaweed. The client was made aware that the cat was slightly overweight and that his estimated daily caloric intake was more than sufficient to maintain his current bodyweight. Concern for inappetence or inadequate intake was not necessary. As the cat would not eat a canned food or soaked kibble, it was suggested to combine the kibble with preferred plant-based treats and foods the cat would eat, while also increasing water intake. The client was advised not to feed more than $10 \%$ of the daily caloric allotment from foods other than the kibble. Additionally, the methionine dose was increased from 250 to $500 \mathrm{mg}$ to acidify the urine.

One month later, the cat was eating the recommended food, but struvite crystalluria persisted and the owner was concerned about inability to increase water intake on the dry extruded diet. The cat was re-presented to the Clinical Nutrition Service, weighing $5.8 \mathrm{~kg}$ with a BCS of 6 on a 9-point scale. A homemade plant-based diet was designed using web-based formulation software $^{1}$ (Tables 3, 4) to meet the AAFCO nutrient profile for adult maintenance with low concentrations of struvite precursors, and utilized ingredients intended to promote urine acidity (12). Acidification of the urine was predicted by calculation of the base excess of the diet (13). Base excess in the food was calculated using the equation: Base excess $(\mathrm{mmol} / \mathrm{kg}$ $\mathrm{DM})=2[\mathrm{Ca}]+2[\mathrm{Mg}]+[\mathrm{Na}]+[\mathrm{K}]-2[\mathrm{P}]-2[\mathrm{Met}]-[\mathrm{Cl}] \quad(13)$. Plant-based fatty acid supplementation was recommended, with plant-based arachidonic acid and EPA+DHA. As the cat was slightly overweight, a conservative energy intake was recommended to just meet his RER of $250 \mathrm{kcal}$ to prevent further weight gain. The next urinalysis performed revealed a stable USG and $\mathrm{pH}$, though struvite crystals were absent. The

${ }^{1}$ Balance $\mathrm{IT}^{\circledR}$. 
TABLE 4 | Homemade feline diet recipe, ingredients listed from highest to lowest inclusion (by weight).

\begin{tabular}{ll}
\hline Client's homemade diet & Formulated diet \\
\hline Firm tofu & Pumpkin \\
Brown rice & Tofu \\
Red lentils & Carrots \\
Sweet potato & Soy protein isolate \\
Carrots & Chestnuts \\
Celery & Beets \\
Pumpkin & Beyond beef \\
Green peas & Nutritional yeast \\
Green beans & Tomato paste \\
Vegetable oil & Balance IT ${ }^{\circledR}$ Feline supplement \\
Apple cider vinegar & Sunflower oil \\
Olives & Pumpkin seeds \\
Kelp powder & Omega-3 fatty acid oil \\
Spirulina or chlorella & Olives \\
Nutritional yeast & Desiccated coconut \\
Dried parsley & Arachidonic acid supplement \\
Catnip & Basil \\
Flax seeds & \\
Vegecat & \\
\hline & \\
\hline supplement & \\
\hline
\end{tabular}

client was encouraged to continue regular rechecks with their family veterinarian, and feedback from the client 9 months later revealed the cat was doing well, he continued to eat a combination of the homemade food and commercial plant-based kibble, his urine was consistently free of struvite crystals, $\mathrm{pH}$ maintained between 6.5-7.0, and the USG below 1.040. The owner reported no further concerns with inappetence, no changes in bodyweight, and the cat had suffered no further FLUTD episodes.

\section{DISCUSSION}

The case report presented here was of a cat with chronic FLUTD of nearly 1-year duration. A complicating factor was the client's request for the diet to be plant-based. There was a lack of client adherence to veterinary therapeutic diet recommendations, resulting in multiple relapses. This case report proposes nutritional counseling and development of a nutrition support plan that fits both the patient's nutritional requirements as well as the owner's lifestyle, habits and beliefs.

Cats evolved consuming a diet comprised exclusively of prey, resulting in evolution of anatomical, physiological, and metabolic adaptations to utilize animal tissues $(14,15)$. These unique adaptations have resulted in the cat being classified as an obligate carnivore (16). With recent interest being shown in feeding plantbased diets to dogs and cats (17), there has been discussion as to the practical and ethical considerations of whether carnivorous animals require animal tissues, per se, or if their exceptional nutritional requirements can be met with animal-free diets enriched with key essential nutrients $(18,19)$. In addition to the challenges of meeting a cat's nutritional requirements from only plant, mineral, and synthetic ingredients, plant-based diets have also been proposed to be a potential risk factor for urinary alkalinization (20) and thus struvite urolithiasis, though this has yet to be substantiated.

In this case, the cat was first presented for urethral obstruction, though no underlying cause (urethral plug, urolith) was reported. The cat did not re-obstruct, but persistently demonstrated other signs of FLUTD. Signs of FLUTD include: dysuria, haematuria, pollakiuria, stranguria, inappropriate urination or obstruction $(2,3)$. There are multiple conditions that fall under the general term of FLUTD that may cause the aforementioned signs, including anatomic abnormalities, urolithiasis, urethral plugs, urethral obstruction, infection, neoplasia, idiopathic inflammation, obstruction, and reflex dyssynergia (21). Given that imaging revealed radiopaque debris in the bladder and urinalysis showed marked crystalluria, it was assumed that struvite, either as uroliths or as a component of a urethral plug, were the primary cause, though other causes of urethral obstruction were not ruled out.

The significance of struvite crystalluria in cats with FLUTD is not known, as healthy cats have been demonstrated to have asymptomatic struvite crystalluria $(22,23)$. However, a recent case report regarding a cat with feline idiopathic cystitis and marked struvite crystalluria (24) supported previous hypotheses that, in the absence of other aetiological agents, persistent urinary signs may be attributable to crystalluria (25-27).

Dietary factors, low water intake, and decreased urination frequency are considered the main risk factors for FLUTD $(3,5,28)$. Thus, promoting large volumes of dilute urine, and simultaneously encouraging frequent urination are the key approaches for nutritional management. Addition of antiinflammatory nutrients such as DHA and EPA may also be beneficial (7). In cases with urolithiasis, additional nutritional interventions are indicated. Considering that struvite crystals are composed of magnesium, ammonium and phosphate, high dietary levels of these nutrients are considered to be causative $(1,29)$. Additionally, other minerals that may affect urinary excretion of phosphorus, such as calcium and chloride may also contribute toward struvite crystalluria. For uroliths to form, the urine environment must favor precipitation of crystals and aggregation of crystals into stones. This requires a high concentration of solutes, urine $\mathrm{pH}$ conducive to precipitation of phosphorus and magnesium, presence of ammonia, and a relatively low urine volume (3). Thus, intervention for dissolution and prevention of struvite urolithiasis is targeted at reducing the formation of struvite crystals and/or impairing the ability of crystals to aggregate into stones (3).

Firstly, controlling intake, and thus, to a degree, excretion of precursor minerals can reduce the substrate for crystal formation (30). The contribution of urinary protein to struvite crystalluria has been less commonly reported but demonstrated in vitro, making consideration of dietary protein levels warranted to reduce protein excretion (31). Protein restriction is not required, but avoidance of protein in gross excess of the recommended intake may be prudent. Concentration of precursors is a component of struvite crystalluria. The presence of ammonia 
and a $\mathrm{pH}>6.0$ are required for precipitation to occur, as high urinary $\mathrm{pH}$ reduces the solubility of phosphorus and magnesium in the urine, allowing the ammonia to bind the minerals leading to precipitation as struvite crystals $(29,31)$. Manipulation of the urinary $\mathrm{pH}$ to maintain a slightly acidic $(\mathrm{pH}<6.5)$ environment thus increases solubility of struvite, reducing crystal precipitation $(30,32)$. Urine $\mathrm{pH}$ can be manipulated by inclusion of acidic sulfur-containing amino acids and minerals such as phosphorus, chloride and sulfur, and restriction of basic minerals, such as calcium, magnesium, sodium, and potassium. Water is also a key consideration in cases with crystalluria and urolithiasis. In order to mitigate aggregation of crystals into stones, urine volume can be increased to reduce urine concentration and saturation and increase frequency of voiding $(3,33)$. By increasing voiding frequency, urine spends less time within the bladder, reducing the time during which uroliths can form and grow (3). High moisture diets are considered a key strategy in prevention of urolithiasis, regardless of composition (34). Manipulation of dietary sodium can also be used to increase voluntary water intake (35).

In this case, veterinary therapeutic diets were unacceptable to the client, due to the presence of animal products. Initially, commercial plant-based products with low magnesium content and base excess supportive of acidic urine formation were identified as alternative recommendations (36). First, canned products were suggested as an effective method of increasing water intake in cats $(3,37)$. Moisture content $>73 \%$ has been reported to increase total water intake and urine volume while decreasing urine specific gravity (38). The canned food had similar magnesium content, but greater protein, sulfur amino acid and moisture content, and a lower base excess than the canned food previously fed (Table 3). It was hypothesized this would lead to more acidic and less concentrated urine. The cat found this canned diet unpalatable and would not eat it, so next an extruded product higher in salt (sodium chloride) was identified to increase water intake $(39,40)$. Additionally, it was recommended to feed multiple smaller meals to encourage more frequent drinking and reduce the magnitude of the postprandial alkaline tide $(41,42)$. Finally, plant-based EPA+DHA and arachidonic acid supplements were recommended. Antiinflammatory effect have been demonstrated for EPA and DHA, while arachidonic acid may help maintain water balance in the kidney, aside from being an essential nutrient for cats (43).

Palatability of the plant-based diets was an issue; the cat consistently refused to consume adequate amounts of diets identified as low risk for FLUTD, but preferred diets unconducive to acidification or production of dilute urine. As a result, the client elected to feed a home-prepared diet. Though the cat preferred to eat the client's home-prepared diet, it was unsuitable not only for dietary management of FLUTD but was also inadequate for adult maintenance as a result of numerous nutrient imbalances (Table 3). A new home-prepared diet was formulated with a nutrient profile more conducive for mitigation of FLUTD. As with the commercial diets, appropriate dietary protein, sulfur amino acids, EPA+DHA, and salt, and lower magnesium were prioritized. Reduction of urine $\mathrm{pH}$ was anticipated by manipulating the base excess of the diet and including sulfur-rich acidifying ingredients (12), while increased urine production was expected by increasing salt and recommendations to add water to the food and stimulate voluntary water intake. Initially, the cat's acceptance of the homemade diet formulated by the nutrition service was also limited, and the owner reported inappetence or disinterest in eating the diet. Over a 2 week period, minor modifications, such as inclusion of olives, tomato paste, and basil per the client's experience, improved the palatability of the diet and eventually the cat accepted the diet and maintained an adequate intake. No further episodes of FLUTD were reported and the client was pleased with the outcome.

None of the commercial PBD were specifically formulated for dissolution or prevention of struvite urolithiasis, nor had any undergone feeding trials to demonstrate either efficacy in promoting urinary tract health or suitability for feline adult maintenance.

Most veterinary therapeutic urinary diets undergo relative supersaturation testing to determine efficacy of dissolution or prevention of struvite uroliths $(38,44)$, but this testing has not been performed for the commercial plant-based or homemade diets. Instead, plant-based diets were selected for nutrient profiles as close as possible to one of several available therapeutic diets. Though the homemade diet was formulated specifically for struvite prevention, no guarantee of efficacy could be made. With the exception of a single timepoint, urinary $\mathrm{pH}$ was consistently neutral (7), not acidic (6-6.5) as intended. The urine concentration fluctuated greatly, but began to trend toward dilution once the homemade diet was initiated. This was not surprising, however, since the homemade diet was fed in conjunction with kibble and assorted treats, potentially contributing toward urinary alkalization. Furthermore, timing of urine collection was not recorded, nor whether urine samples were fasted or fed, all factors that influence urine $\mathrm{pH}$. Though failure to acidify the urine was a clear limitation in the application of the homemade diet, resolution of clinical signs and improvement in other urinary parameters suggests adequate dietary modification to prevent FLUTD in this cat, at least during the 9 months of follow-up.

Ideally, any cat with a history of recurrent FLUTD and crystalluria should be monitored closely with repeat urinalyses every 3-6 months. Specifically, changes in $\mathrm{pH}$ (particularly increases in $\mathrm{pH}$ ), increase in urine specific gravity, presence of protein in the urine or increases in crystalluria would warrant investigation and potentially a change to the diet. For a cat fed an unconventional diet, including a plantbased diet, further monitoring at 6-monthly intervals would be desired to ensure the cat is able to maintain general wellness by routine physical examination, complete blood count, and serum biochemistry.

\section{CONCLUSION}

Management of FLUTD is complex and multifactorial, with appropriate nutrition and feeding a critical component. This case presented a greater challenge due to the client's preference for a plant-based diet, as there are no diets formulated and 
tested for management of FLUTD that do not contain animal ingredients. Commercial plant-based diets with nutrient profiles closest to that recommended for FLUTD were trialed but not accepted, culminating in formulation of a homemade plant-based diet. Unlike veterinary therapeutic diets that have undergone RSS testing and/or clinical trials, there is no evidence to support the efficacy of homemade formulations for mitigation of FLUTD, crystalluria, or urolithiasis. Nevertheless, 9 months post-intervention, the cat was reported by the client to be healthy and well.

\section{DATA AVAILABILITY STATEMENT}

The original contributions presented in the study are included in the article/supplementary material, further inquiries can be directed to the corresponding author/s.

\section{REFERENCES}

1. Lekcharoensuk C, Osborne C, Lulich J. Epidemiologic study of risk factors for lower urinary tract diseases in cats. J Am Vet Med Assoc. (2001) 218:142935. doi: 10.2460/javma.2001.218.1429

2. Kaul E, Hartmann K, Reese S, Dorsch R. Recurrence rate and long-term course of cats with feline lower urinary tract disease. J Feline Med Surg. (2020) 22:544-56. doi: 10.1177/1098612X19862887

3. Kerr K. Dietary management of feline lower urinary tract symptoms. J Anim Sci. (2013) 91:2965-75. doi: 10.2527/jas.2012-6035

4. Houston D, Vanstone N, Moore A, Weese H, Weese J. Evaluation of 21426 feline bladder urolith submissions to the canadian veterinary urolith centre (1998-2014). Can Vet J. (2016) 75:196-201.

5. Osborne C, Lulich J, Kruger J, Ulrich L, Koehler L. Analysis of 451,891 canine uroliths, feline uroliths, and feline urethral plugs from 1981 to 2007: Perspectives from the minnesota urolith center. Vet Clin North Am Small Anim Pract. (2008) 39:183-97. doi: 10.1016/j.cvsm.2008.09.011

6. Escolar E, Bellanato J. Analysis of feline urinary calculi and urethral plugs by infrared spectroscopy and scanning electron microscopy. Vet Rec. (2003) 152:625-28. doi: 10.1136/vr.152.20.625

7. Forrester S, Kruger J, Allen T. Feline lower urinary tract diseases. In: Hand MS, Thatcher CD, Remillard RL, Roudebush P, Novotny BJ, editors. Small Animal Clinical Nutrition. 5th ed. Topeka, KS: Mark Morris Institute (2010). p. 925-76.

8. WSAVA. Body Condition Score (Cat). Global Nutrition Toolkit (2013). Available online at: https://www.wsava.org/WSAVA/media/Arpita-andEmma-editorial/Body-Condition-Score-Cat.pdf (accessed September 24, 2020).

9. WSAVA. Nutritional Assessment Checklist. (2013). Available online at: https:// www.wsava.org/WSAVA/media/Arpita-and-Emma-editorial/NutritionalAssessment-Checklist.pdf (accessed September 24, 2020).

10. Gross K, Yamka R, Khoo C, Friesen K, Jewell D, Schoenherr W, et al. Macronutrients. In: Hand MS, Thatcher CD, Remillard RL, Roudebush P, Novotny BJ, editors. Small Animal Clinical Nutrition. 5th ed. Topeka, KS: Mark Morris Institute (2010). p. 49-105.

11. Dodd S, Shoveller A, Ma D, Fascetti A, Yu Z, Verbrugghe A. Comparison of essential nutrients in plant-based pet foods to the estimated nutrient requirements of dogs and cats. In: ACVIM Forum. Baltimore, MD (2020).

12. Halfen D, Kessler AdM, Trevizan L, Jeremias J, Vendramini T, Santos J, et al. Different sources of sulfur in diets of adult cats on the urinary parameters and acid-base balance. Ciênc Rural. (2018) 48:e20180017. doi: 10.1590/0103-8478cr201 80017

13. Kienzle E, Schuknecht A, Meyer H. Influence of food composition on the urine ph in cats. J Nutr. (1991) 121:S87-8. doi: 10.1093/jn/121.suppl_11.S87

\section{ETHICS STATEMENT}

Ethical review and approval was not required for the animal study because this case report describes clinical treatment of a privately owned animal. Written informed consent was obtained from the owners for the participation of their animals in this study.

\section{AUTHOR CONTRIBUTIONS}

SD was veterinarian directly managing this case with CG's support. AV and SA supervised and mentored SD. SD wrote the report with assistance and feedback from CG, AV, and SA. All authors contributed to the article and approved the submitted version.

14. Verbrugghe A, Bakovic M. Peculiarities of one-carbon metabolism in the strict carnivorous cat and the role in feline hepatic lipidosis. Nutrients. (2013) 5:2811-35. doi: 10.3390/nu5072811

15. Plantinga E, Bosch G, Hendriks W. Estimation of the dietary nutrient profile of free-roaming feral cats: possible implications for nutrition of domestic cats. Br J Nutr. (2011) 106:S35-48

16. Morris J. Idiosyncratic nutrient requirements of cats appear to be diet-induced evolutionary adaptations. Nutr Res Rev. (2002) 15:15368. doi: 10.1079/NRR200238

17. Dodd S, Cave N, Adolphe J, Shoveller A, Verbrugghe A. Plant-based (vegan) diets for pets: a survey of pet owner attitudes and feeding practices. PLoS ONE. (2019) 14:e0210806. doi: 10.1371/journal.pone.0210806

18. Gray C, Sellon R, Freeman L. Nutritional adequacy of two vegan diets for cats. J Am Vet Med Assoc. (2004) 225:1670-75. doi: 10.2460/javma.2004.225.1670

19. Semp P. Vegan nutrition of dogs and cats. [Master's thesis]. Veterinary University of Vienna, Vienna, Austria (2014).

20. Knight A, Leitsberger M. Vegetarian versus meat-based diets for companion animals. Animals. (2016) 65:57. doi: 10.3390/ani6090057

21. Osborne C, Kruger J, Lulich J. Feline lower urinary tract disorers. Definition of terms and concepts. Vet Clin North Am Small Anim Pract. (1996) 26:16979. doi: 10.1016/S0195-5616(96)50200-7

22. Gunn-Moore D. Feline lower urinary tract disease. J Feline Med Surg. (2003) 5:133-38. doi: 10.1016/S1098-612X(02)00129-8

23. Hostutler R, Chew D, DiBartola S. Recent concepts in feline lower urinary tract disease. Vet Clin North Am Small Anim Pract. (2005) 35:14770. doi: 10.1016/j.cvsm.2004.08.006

24. Bell E, Lulich J. Marked struvite crystalluria and its association with lower urinary tract signs in a cat with feline idiopathic cystitis. Austr Vet J. (2015) 93:332-35. doi: 10.1111/avj.12353

25. Gevaert D, De Smet B, De Wilde R. Dietary treatment of progressive feline struvite crystalluria. J Small Anim Pract. (1994) 35:575-80. doi: 10.1111/j.1748-5827.1994.tb03823.x

26. Gerber B, Eichenberger S, Reusch C. Guarded long-term prognosis in male cats with urethral obstruction. J Feline Med Surg. (2008) 10:1623. doi: 10.1016/j.jfms.2007.06.007

27. Lund H, Krontveit R, Halvorsen I, Eggertsdóttir A. Evaluation of urinalyses from untreated adult cats with lower urinary tract disease and healthy control cats: predictive abilities and clinical relevance. J Feline Med Surg. (2013) 15:1086-97. doi: 10.1177/1098612X13492739

28. Houston D, Moore A, Favrin M, Hoff B. Feline urethral plugs and bladder uroliths: A review of 5484 submissions 1998-2003. Can Vet J. (2003) 44:97477.

29. Gomes V, Ariza P, Borges N, Schulz F Jr., Fioravanti M. Risk factors associated with feline urolithiasis. Vet Res Commun. (2018) 42:8794. doi: 10.1007/s11259-018-9710-8 
30. Tefft KM, Byron JK, Hostnik ET, Daristotle L, Carmella V, Frantz N. Effect of a struvite dissolution diet in cats with naturally occurring struvite urolithiasis. J Feline Med Surg. (2021) 23:269-77. doi: 10.1177/1098612X20942382

31. Matsumoto K, Funaba M. Factors affecting struvite (mgnh4po46h2o) crystallization in feline urine. Biochimicha et Biophysica Acta. (2008) 1780:233-39. doi: 10.1016/j.bbagen.2007.09.013

32. Bartges J, Kirk C, Cox S, Moyers T. Influence of acidifying or alkalinizing diets on bone mineral density and urine relative supersaturation with calcium oxalate and struvite in healthy cats. Am J Vet Res. (2013) 74:134752. doi: 10.2460/ajvr.74.10.1347

33. Torres-Henderson C, Bunkers J, Contreras E, Cross E, Lappin M. Use of purina pro plan veterinary diet ur urinary st/ox to dissolve struvite cystoliths. Top Comp Anim Med. (2017) 32:49-54. doi: 10.1053/j.tcam.2017.07.007

34. Lulich J, Berent A, Adams L, Westropp J, Bartges J, Osborne C. Acvim small animal consensus recommendations on the treatment and prevention of uroliths in dogs and cats. J Vet Int Med. (2016) 30:156474. doi: 10.1111/jvim.14559

35. $\mathrm{Xu} \mathrm{H}$, Laflamme D, Long G. Effects of dietary sodium chloride on health parameters in mature cats. J Feline Med Surg. (2009) 11:43541. doi: 10.1016/j.jfms.2008.10.001

36. Lulich J, Kruger J, MacLeay J, Merrills J, Paetau-Robinson I, Albasan H, et al. Efficacy of two commercially available, low-magnesium, urine-acidifying dry foods for the dissolution of struvite uroliths in cats. J Am Vet Med Assoc. (2013) 243:1147-53. doi: 10.2460/javma.243.8.1147

37. Carciofi A, Bazolli R, Zanni A, Kihara L, Prada F. Influence of water content and the digestibility of pet foods on the water balance of cats. Brazil J Vet Res Anim Sci. (2005) 42:429-34. doi: 10.11606/issn.1678-4456.bjvras.2005.26401

38. Buckley C, Hawthorne A, Colyer A, Ae S.Effect of dietary water intake on urinary output, specific gravity and relative supersaturation for calcium oxalate and struvite in the cat. Br J Nutr. (2011) 106:S12830. doi: 10.1017/S0007114511001875

39. Markwell P, Buffington C, Smith B. The effect of diet on lower urinary tract diseases in cats. J Nutr. (1998) 128:2753S-57S. doi: 10.1093/jn/128.12.2753S

40. Hawthorne A, Markwell P. Dietary sodium promotes increased water intake and urine volume in cats. J Nutr. (2004) 134:2128S-29S. doi: 10.1093/jn/134.8.2128S
41. Kirschvink N, Lhoest E, Leemans J, Delvaux F, Istasse L, Gustin P, et al. Effects of feeding frequency on water intake in cats. In: ACVIM Forum. Baltimore, MD: American College of Veterinary Internal Medicine Record (2005).p. 476-76.

42. Finke M, Litzenberger B. Effect of food intake on urine ph in cats. J Small Anim Pract. (1992) 33:261-65. doi: 10.1111/j.1748-5827.1992. tb01135.x

43. Hall J, Brockman J, Davidson S, MacLeay J, Jewell D. Increased dietary long-chain polyunsaturated fatty acids alter serum fatty acid concentrations and lower risk of urine stone formation in cats. PLoS ONE. (2017) 12:e0187133. doi: 10.1371/journal.pone. 0187133

44. Houston D, Weese H, Evason M, Biourge V, van Hoek I. A diet with a struvite relative supersaturation less than 1 is effective in dissolving struvite stones in vivo. Br J Nutr. (2011) 106:S90-2. doi: 10.1017/S0007114511 000894

Conflict of Interest: The authors declare that SD is the owner of Dodd Veterinary Services and provides both veterinary care and nutritional consultation to private clients and industry partners. CG holds the Nestlé Purina Professorship in Companion Animal Nutrition at the Ontario Veterinary College, is the owner of Grant Veterinary Nutrition Services and consults with Simmons Pet Food. SA is the owner of Sit, Stay Speak Nutrition LLC and provides nutrition consultation to industry partners. AV is the Royal Canin Veterinary Diets Endowed Chair in Canine and Feline Clinical Nutrition at the Ontario Veterinary College, serves on the Health and Nutrition Advisory Board for Vetdiet and has received honoraria and research funding from various pet food manufacturers and ingredient suppliers.

Copyright (c) 2021 Dodd, Grant, Abood and Verbrugghe. This is an open-access article distributed under the terms of the Creative Commons Attribution License (CC BY). The use, distribution or reproduction in other forums is permitted, provided the original author(s) and the copyright owner(s) are credited and that the original publication in this journal is cited, in accordance with accepted academic practice. No use, distribution or reproduction is permitted which does not comply with these terms. 